\title{
Load Frequency Control for Two Area Power System Using Different Controllers
}

\author{
Dr.D.V.Kumar, \\ Professor, Department of Electrical and Electronics, S.V.C.E, Tirupati, Andhra Pradesh, India
}

\begin{abstract}
Automatic Generation Control (AGC) or Load Frequency Control is a very important issue in power system operation and control for supplying sufficient and reliable electric power with good quality. AGC is a feedback control system adjusting a generator output power to remain defined frequency. One of the objectives of AGC is to maintain the system frequency at nominal value In the steady state operation of power system .An extended power system can be divided into a number of load frequency control areas interconnected by means of tie lines. Without loss of generality one can consider a three- area case connected by tie line. Here we are considering system, which is integration of two thermal power systems with hydro power system. That is area- 1 and area- 2 consists of thermal reheat power plant whereas area-3 consists of hydro power plant. The performance analysis of load frequency control for multi area inter connected system will be done in MATLAB/SIMULINK environment. As integration of multi area effects performance of system study of different characteristics using controllers like conventional PI ,PID, artificial intelligence FUZZY LOGIC controlling techniques are necessary in order to determine the effective gains of controller in efficient manner. And this knowledge about dynamic response characteristics will give us idea of controlling techniques that we need to implement for obtaining required frequency response at tie line stations.
\end{abstract}

KEYWORDS: load frequency control, multi area power system proportional Integral, proportional integral derivative controlling techniques, fuzzy logic.

\section{INTRODUCTION}

Electrical Power systems are interconnected to provide secure and economical operation. [1]The main objective of automatic generation controller (AGC) is to maintain the balance between the generation and demand of a particular power system. The problem of controlling the real power output of generating units in response to changes in system frequency and tie-line power interchange within specified limits is known as load frequency control (LFC) [1]. The Objectives of LFC are to provide zero steady-state error of frequency and tie-line exchange variations, high damping of frequency oscillations and decreasing overshoot of the disturbance so that the system is not too far from the stability [2]. The interconnected power system is typically divided into control areas, with each consisting of one or more power utility companies. Sufficient supply for generation of each connected area to meet the load demand of its customers.

The above mentioned objectives are carried successfully in previous works by different authors using PI and PID controllers [4] \& [5]. The interconnected power system is typically divided into control areas, with each consisting of one or more power utility companies. Sufficient supply for generation of each connected area to meet the load demand of its customers. In this paper Fuzzy Logic Controller (FLC) is used [10]. This type of controller adds a pole at origin resulting in system type so reducing the steady state error. System load is never steady using controller these can be controlled. When uncontrolled case more oscillation, negative overshoot be observed but while comparing to conventional type controller PID and propose work result gives better performances of dynamic responses.

\section{CONTROLLER}

There are many types of controller such like proportional, integral, derivative and combinational of these (PI, PID).

\subsection{PID CONTROLLER}

The block diagram of Proportional Integrative Derivative (PID) controller is shown in Fig.1. 


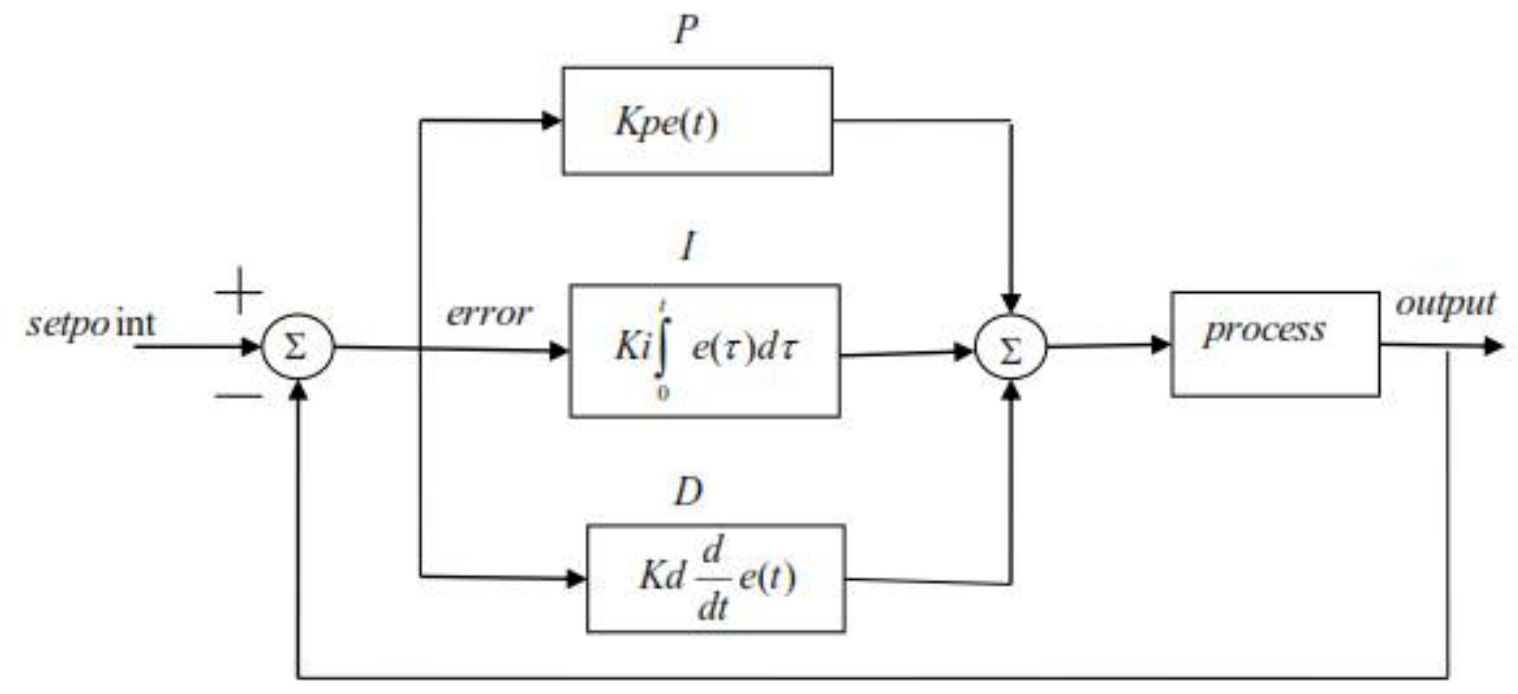

Figure 1: Block diagram of a PID controller.

The PID controller improves the transient response so as to reduce error amplitude with each oscillation and then output is eventually settled to a final desired value. Better margin of stability is ensured with PID controllers. The mathematical equation for the PID controller is given as [4] \& [9].

$$
\mathrm{y}(\mathrm{t})=K p e(t)+K i \int_{0}^{t} e(\tau) d \tau+K d \frac{d}{d t} e(t)
$$

Where $\mathrm{y}(\mathrm{t})$ is the controller output and $\mathrm{u}(\mathrm{t})$ is the error signal. $\mathrm{K} p, \mathrm{~K} i$ and $\mathrm{K} d$ are proportional, integral and derivative gains of the controller. The limitation conventional PI and PID controllers are slow and lack of efficiency in handling system non-linearity. Generally these gains are tuned with help of different optimizing methods such as Ziegler Nicholas method, Genetic algorithm, etc., the optimum gain values once obtained is fixed for the controller. But in the case deregulated environment large uncertainties in load and change in system parameters is often occurred. The optimum controller gains calculated previously may not be suitable for new conditions, which results in improper working of controller. So to avoid such situations the gains must be tuned continuously.

\subsection{FUZZY LOGIC CONTROLLER}

Since power system dynamic characteristics are complex and variable, conventional control methods cannot provide desired results. Intelligent controller can be replaced with conventional controller to get fast and good dynamic response in load frequency problems. Fuzzy Logic Controller (FLC) can be more useful in solving large scale of controlling problems with respect to conventional controller are slower.

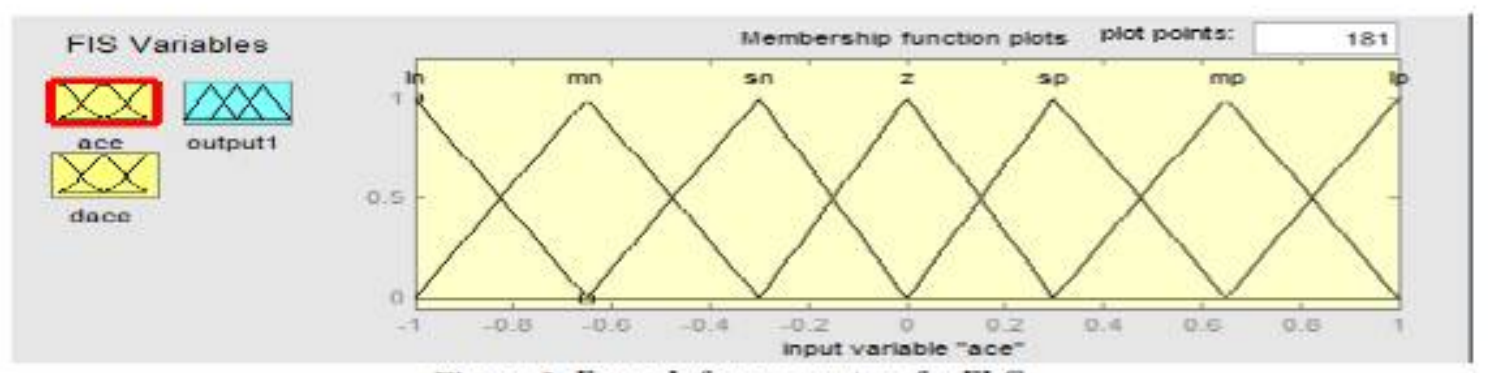

Figure 2. Fuzzy Inference system for FLC

Fuzzy logic controller is designed to minimize fluctuation on system outputs. There are many studied on power system with fuzzy logic controller consist of three section namely fuzzifier, rule base and defuzzifier as shown in fig.2.[9] gives idea for the different steps of interference system[10].

The membership functions are decided according to input data or available data from these rules are to be designed.

The error e and change in error de are inputs of FLC. Two inputs signals are converted to fuzzy numbers first in fuzzifier using five membership functions. Positive Big (PB), Positive Small(PS), 
Zero (ZZ),Negative Small(NS),Negative Big (NB), Small (S), Medium (M), Big (B), very Big (VB), Very Very Big (VVB). Finally resultant fuzzy subsets representing the controller output are converted to the crisp values using the central of area (COA) defuzzifier scheme

\section{MODEL OF TWO AREA POWER SYSTEM}

Each area is assumed to have only one equivalent generator and is equipped with governor- turbine system. They are the control signals from the controllers we choose. The plant for a power system with a non-reheated turbine consists of three parts:

- Governor with dynamics:

$$
\begin{aligned}
& G_{\mathrm{g}}(\mathrm{s})=\frac{1}{T G s+1} . \\
& \mathrm{G}_{\mathrm{t}}(\mathrm{s})=\frac{1}{T T s+1} .
\end{aligned}
$$

- Turbine with dynamics:

- Load and machine with dynamics: $\quad \mathrm{G}_{\mathrm{p}}(\mathrm{s})=\frac{K p}{T P s+1}$.

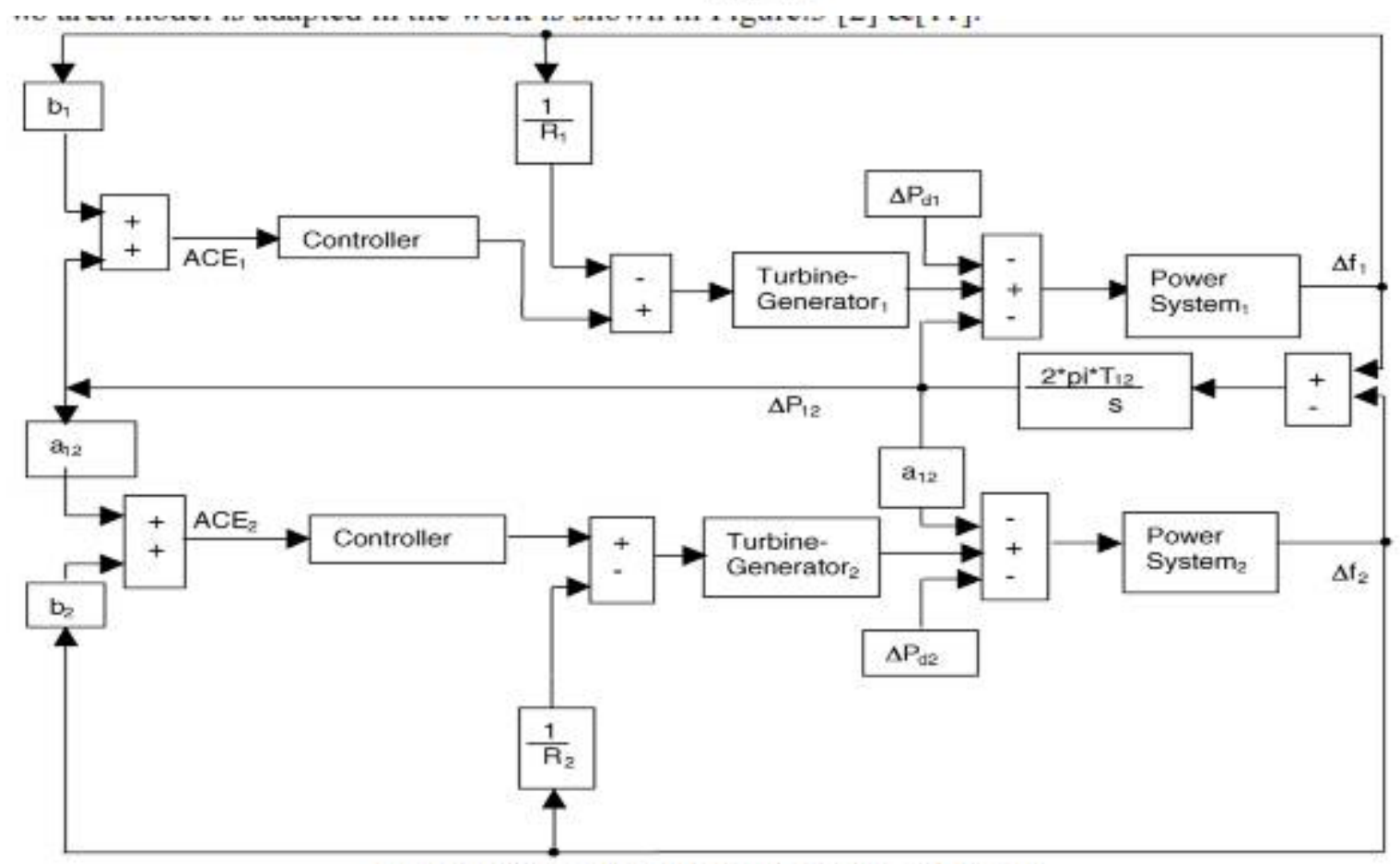

Figure 3: Block diagram of two area power system.

\section{MATLAB SIMULINK MODEL}

\subsection{Power System Model using Different Controllers}

In two area system, two single area systems are interconnected via tie-line. Interconnections established increases the overall system reliability. Even if some generating units in one area fail, the generating units in the other area can compensate to meet the load demand. The basic block diagram of five area interconnected power system is shown in Fig.2. A conventional integral controller is used on a power system model. The PID controller improves steady state error simultaneously allowing a transient response with little or no overshoot. As long as error remains, the integral output will increase causing the speed changer position, attains a constant value only when the frequency error has reduced to zero. The SIMULINK model of a two area interconnected power system using PID controller is shown in Figure 4 [6]. 


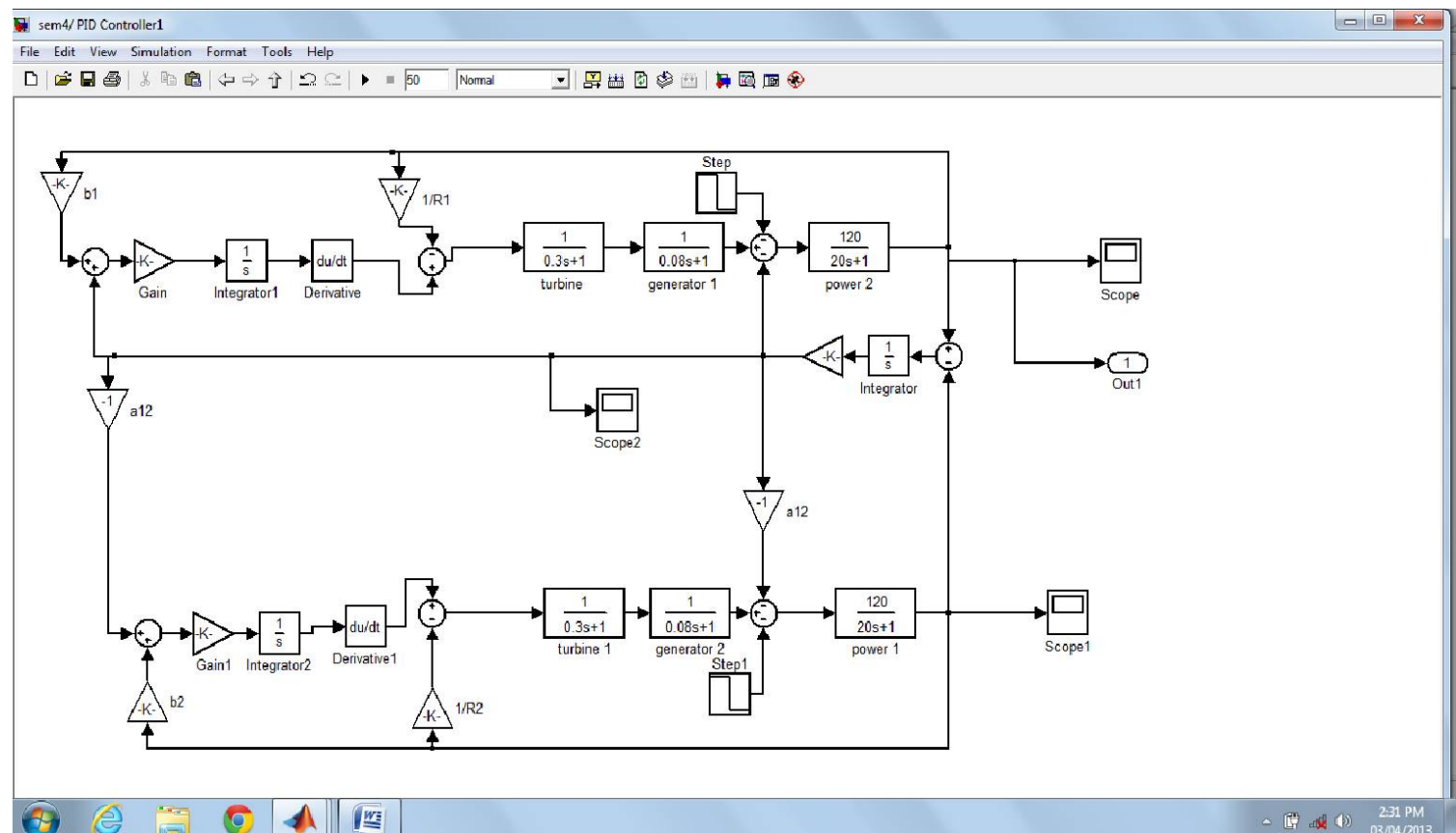

Figure 4: Simulink model of two area power system using PID controller.

The output response is shown in Fig.5, which having the comparison results between simple integral (I), proportional integral (PI), Proportional integral derivative (PID).

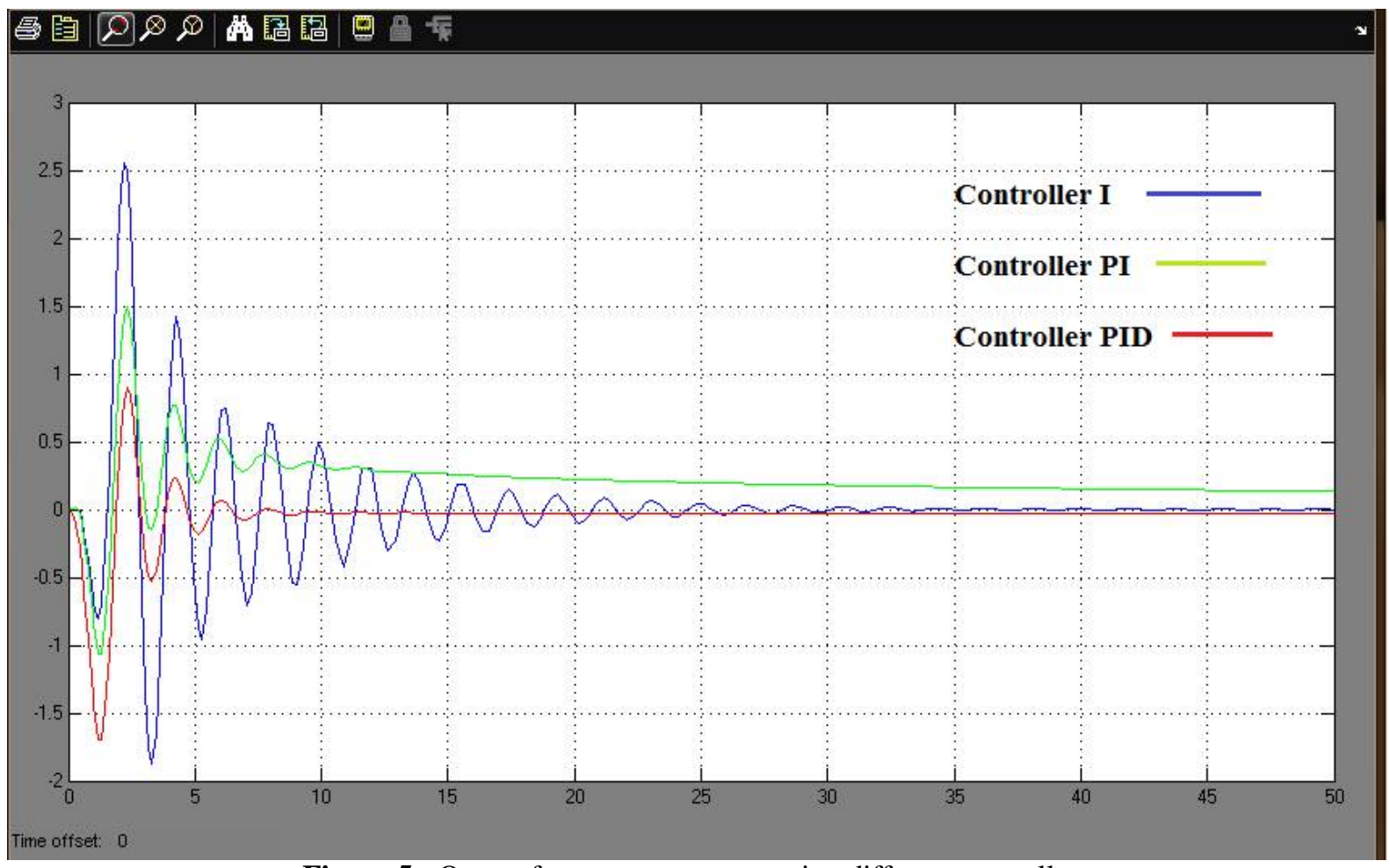

Figure 5: Output frequency response using different controller. 
International Journal of Advanced Research in Electrical, Electronics and Instrumentation Engineering Vol. 2, Issue 3, March 2013

The gain value of different types of controller using in two area power system is given in Table 1.

Table 1: Different values of gain for different controllers

\begin{tabular}{|l|l|l|l|l|l|l|l|}
\cline { 2 - 8 } \multicolumn{1}{c|}{} & \multicolumn{2}{c|}{ Kp } & \multicolumn{2}{c|}{ Ki } & \multicolumn{2}{c|}{ Kd } & $\begin{array}{l}\text { Settling } \\
\text { time } \\
\text { (sec.) }\end{array}$ \\
\hline Controller & Areal & Area2 & Areal & Area 2 & Area 1 & Area 2 & \\
\hline I & - & - & 0.2742 & 0.4680 & - & - & 35 \\
\hline PID & 0.1109 & 0.0121 & 0.2742 & 0.2019 & - & - & 25 \\
\hline
\end{tabular}

It shows that for different controllers getting different settling time value. The settling time of PID controller is less than I, PI controller. We can control oscillations, rise time and settling time using different control method.

\subsection{Power system Model using fuzzy Logic controller}

In this type of controller gain value of controller is automatically fixed. The MATLAB Simulink diagram is shown in Figure 6.

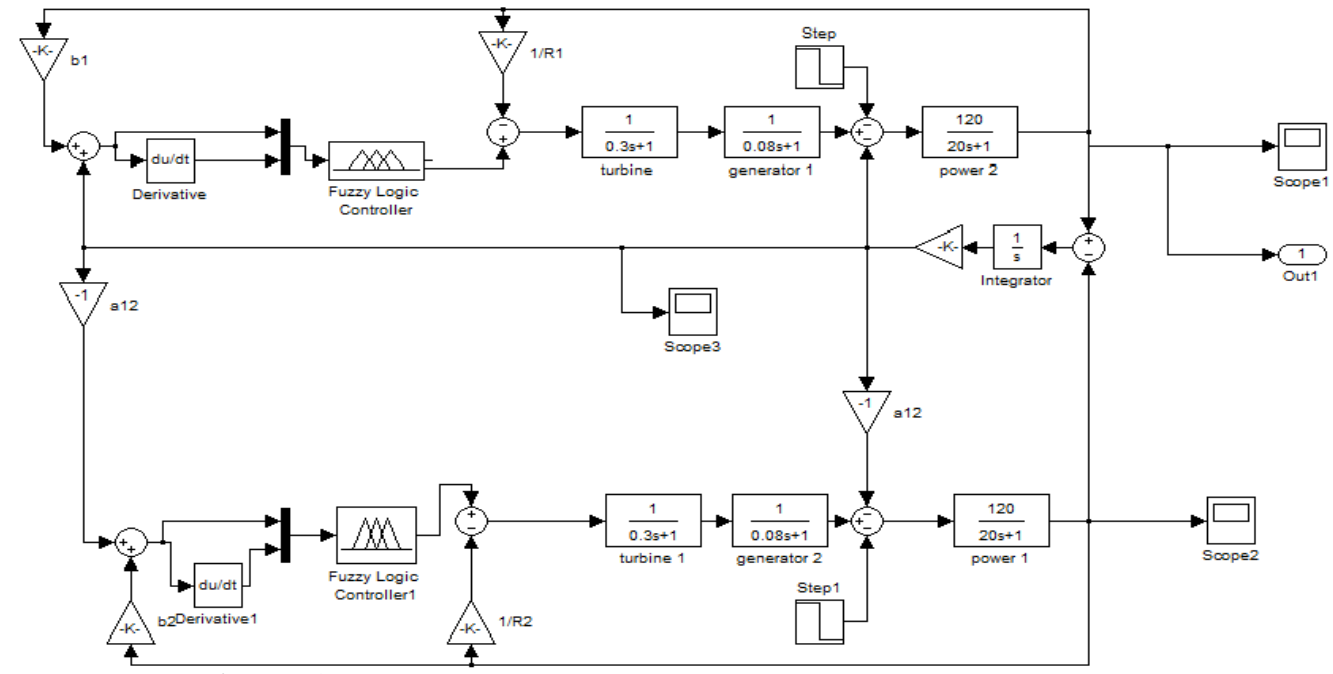

Figure 6: Simulink model of two area power system using PID tuning controller.

The output response of PID tuning method for area1, area 2 and Tie-line is shown in Fig.7, Fig. , and Fig.9 respectively.

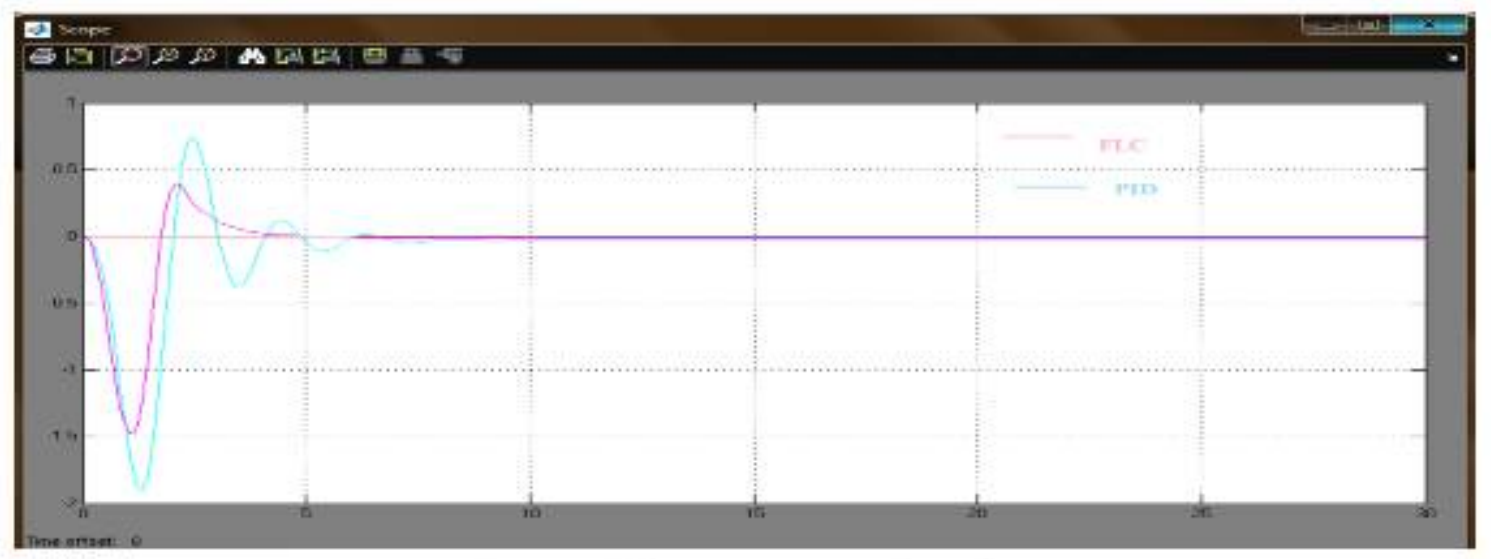

Figure 7: Outbut resbonse of area 1. 
ISSN (Print) : $2320-3765$

ISSN (Online): 2278 - 8875

International Journal of Advanced Research in Electrical, Electronics and Instrumentation Engineering Vol. 2, Issue 3, March 2013

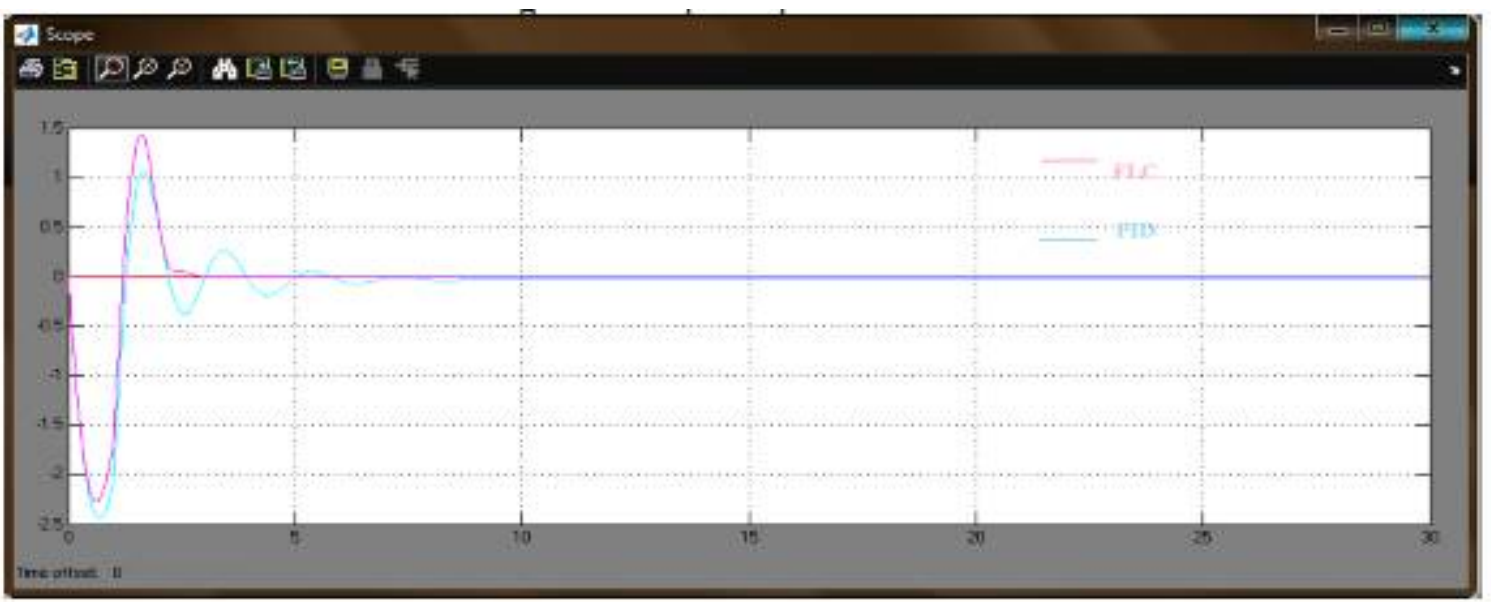

Figure 8: Output response of area 2.

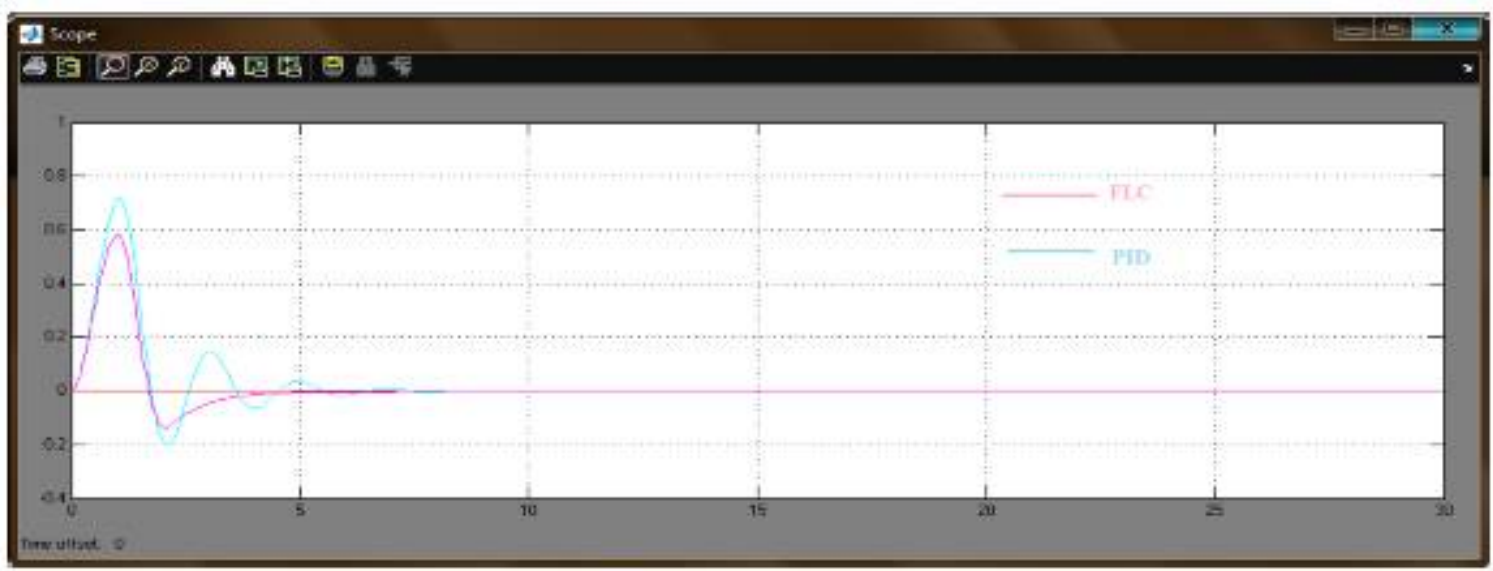

Figure 9: Output response of tie-line of power system.

\section{CONCLUSIONS}

A PID controller used for load frequency controller of two area interconnected power system has been presented. It can be implemented in four area power system and controlled by using advanced controller systems. The system performance was observed on the basis of dynamic parameters i.e. settling time, overshoot and undershoot. The system performance characteristics reveals that the performance of fuzzy logic controller method better than other controllers. As a further study, the proposed method can be applied to multi area power system load frequency control (ALFC) and also optimum values can be obtained by Genetic Algorithm and Neural networks.

\section{REFERENCES}

[1].Wen Tan, Unified tuning of PID load frequency controller for power system via IMC,IEEE Trans. Power Systems, vol. 25, no. 1, pp. 341-350, 2010 .

[2].G. Raj Goutham,Dr. B. Subramanyam, IMC Tuning of PID Load Frequency Controller and Comparing Different Configurations for Two Area Power System, International Journal of Engineering Research and Applications, Vol. 2, Issue 3, May-Jun 2012,pp.1144-1150.

[3].Emre Ozkop, Ismail H. Altas, Adel M. Sharaf, Load Frequency Control in Four Area Power Systems Using Fuzzy Logic PI Controller,16 th National Power Systems Conference, 15th-17th Dec., 2010.

[4].K. P. Singh Parmar, S. Majhi, D. P. Kothari, Optimal Load Frequency Control of an Interconnected Power System, MIT International Journal of Electrical and Instrumentation Engineering, vol. 1, No. 1, pp 1-5, Jan 2011.

[5].Mohammad Soroush Soheilirad, Mohammad Ali Jan Ghasab, Seyed mohammed hossein Sefidgar, Amin mohammad Saberian, Tuning of PID Controller for Multi Area Load Frequency Control by Using Imperialist Competitive Algorithm, J. Basic. Appl. Sci.Res., 2(4)3461-3469, 2012

[6].Akanksha Sharma, K.P. Singh Parmar and Dr. S.K. Gupta, Automatic Generation Control of Multi Area Power System using ANN Controller, International Journal of Computer Science and Telecommunications [vol. 3, Issue 3, March 2012]

[7].S. Ganapathy, S. Velusami, Design of MOEA based Decentralized Load-Frequency Controllers for Interconnected Power Systems with AC-DC Parallel Tie-lines, International Journal of Recent Trends in Engineering, Vol 2, No. 5, November 2009.

[8].R. Francis, Dr. I. A. Chidambaram, Automatic Generation Control for an Interconnected Reheat Thermal Power Systems Using Wavelet Neural Network Controller, International Journal of Emerging Technology and Advanced Engineering Website: www.ijetae.com (ISSN 2250-2459, Volume 2, Issue 4, April 2012) 
ISSN (Print) : $2320-3765$

ISSN (Online): 2278 - 8875

International Journal of Advanced Research in Electrical, Electronics and Instrumentation Engineering

Vol. 2, Issue 3, March 2013

[9].K. Rama Sudha, V.S. Vakula, R. Vijaya Shanthi, PSO based Design of Robust Controller for Two Area Load Frequency Control with Nonlinearities, International Journal of Engineering Science and Technology, Vol. 2(5), 2010, 1311-1324

[10].G. Karthikeyan, S. Ramya, Dr. S. Chandrasekar, Load Frequency Control for Three Area System with Time Delays Using Fuzzy Logic Controller," International Journal of Engineering Science \& Advanced Technology, ISSN: 2250-3676 Volume-2, Issue-3, 612 - 618.

[11].Kanika Wadhwa, Sourav Choubey, Pardeep Nain ,Study of Automatic Generation Control Of two area thermal-thermal system with GRC and without GRC, First National conference on Power System Engineering(PSEC'12) Paper code PS1015 